\title{
The CXCL12gamma chemokine immobilized by heparan sulfate on stromal niche cells controls adhesion and mediates drug resistance in multiple myeloma
}

Zemin Ren ${ }^{1,2}$, Hildo Lantermans ${ }^{1,2}$, Annemieke Kuil ${ }^{1,2}$, Willem Kraan ${ }^{1,2}$, Fernando Arenzana-Seisdedos ${ }^{3}$, Marie José Kersten ${ }^{2,4}$, Marcel Spaargaren ${ }^{1,2+}$ and Steven T. Pals ${ }^{1,2^{*}}$

\begin{abstract}
Background: The survival and proliferation of multiple myeloma (MM) cells in the bone marrow (BM) critically depend on interaction with stromal cells expressing the chemokine CXCL12. CXCL12 regulates the homing to the BM niche by mediating the transendothelial migration and adhesion/retention of the MM cells. The gamma isoform of CXCL12 (CXCL12 $\gamma$ ) has been reported to be highly expressed in mouse BM and to show enhanced biological activity compared to the 'common' CXCL12a isoform, mediated by its unique extended C-terminal domain, which binds heparan sulfate proteoglycans (HSPGs) with an extraordinary high affinity.Here, we investigated the expression of CXCL12 $\gamma$ in human BM and studied its functional role in the interaction of MM cells with BM stromal cells (BMSCs).

Methods: We assessed CXCL12y mRNA and protein expression by human BMSCs using qPCR, flow cytometry, and immunohistochemistry. CRISPR-Cas9 was employed to delete CXCL12 $\gamma$ and the heparan sulfate (HS) co-polymerase EXT1 in BMSCs. To study the functional roles of BMSC-derived CXCL12 $\gamma$ and HSPGs in the interaction of MM cells with BMSCs cells, MM cell lines and primary MM cells were co-cultured with BMSCs.

Results: We observed that CXCL12 $\gamma$ is expressed in situ by reticular stromal cells in both normal and MM BM, as well as by primary BMSC isolates and BMSC lines. Importantly, upon secretion, CXCL12 $\gamma$, unlike the CXCL12a isoform, was retained on the surface of BMSCs. This membrane retention of CXCL12y is HSPG mediated, since it was completely annulated by CRISPR-Cas9-mediated deletion of the HS co-polymerase EXT1. CXCL12 $\gamma$ expressed by BMSCs and membrane-retained by HSPGs supported robust adhesion of MM cells to the BMSCs. Specific genetic deletion of either CXCL12 $\gamma$ or EXT1 significantly attenuated the ability of BMSCs to support MM cell adhesion and, in addition, impaired their capacity to protect MM cells from bortezomib-induced cell death.

Conclusions: We show that CXCL12 $\gamma$ is expressed by human BMSCs and upon secretion is retained on their cell surface by HSPGs. The membrane-bound CXCL12 $\gamma$ controls adhesion of MM cells to the stromal niche and mediates drug resistance. These findings designate CXCL12 $\gamma$ and associated HSPGs as partners in mediating MM-niche interaction and as potential therapeutic targets in MM.
\end{abstract}

\footnotetext{
*Correspondence: s.t.pals@amsterdamumc.nl

${ }^{\dagger}$ Marcel Spaargaren and Steven T. Pals share the last authorship

1 Department of Pathology, Amsterdam University Medical Centers, Loc.

AMC, Meibergdreef 9, 1105 AZ Amsterdam, The Netherlands

Full list of author information is available at the end of the article
}

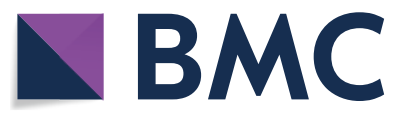

(c) The Author(s) 2021. Open Access This article is licensed under a Creative Commons Attribution 4.0 International License, which permits use, sharing, adaptation, distribution and reproduction in any medium or format, as long as you give appropriate credit to the original author(s) and the source, provide a link to the Creative Commons licence, and indicate if changes were made. The images or other third party material in this article are included in the article's Creative Commons licence, unless indicated otherwise in a credit line to the material. If material is not included in the article's Creative Commons licence and your intended use is not permitted by statutory regulation or exceeds the permitted use, you will need to obtain permission directly from the copyright holder. To view a copy of this licence, visit http://creativecommons.org/licenses/by/4.0/. The Creative Commons Public Domain Dedication waiver (http://creativeco mmons.org/publicdomain/zero/1.0/) applies to the data made available in this article, unless otherwise stated in a credit line to the data. 
Keywords: Multiple myeloma, CXCL12, Heparan sulfate proteoglycans, Bone marrow stromal cells, Adhesion, Drug resistance

\section{Background}

The uncontrolled growth of cancer cells is driven by mutations in essential growth control genes, but their growth and survival are also strongly dependent on signals from the tumor microenvironment. In multiple myeloma (MM), a clonal expansion of malignant plasma cells in the bone marrow (BM), the interaction with specific BM niches plays an important role in tumor cell proliferation and survival. This interaction involves signaling via cell surface receptors, including adhesion molecules, as well as by soluble factors secreted by various cells in the BM niche [1-3]. Despite improved survival due to the introduction of proteasome inhibitors, immunomodulatory drugs, and, more recently, monoclonal antibodies targeting MM cells [4-6], MM is generally still incurable, which is largely due to the development of therapy resistance. MM cell interaction with the BM niche is believed to play a key role in this resistance; hence, targeting this interaction presents a promising therapeutic strategy $[1$, $7,8]$.

The homing of hematopoietic stem cells (HSCs) as well as plasma cell precursors to the BM is controlled by the chemokine CXCL12 $[9,10]$. This chemokine also regulates the adhesion, transendothelial migration, and homing of MM cells to the BM by binding its receptor CXCR4 on the MM cells [11-13]. In the BM microenvironment, CXCL12 is mainly produced by specialized reticular BMSCs, also referred to as 'CXCL12-abundant reticular (CAR)' cells. Several splice variants of CXCL12 have been identified [14], which all contain the CXCR4binding motif but are differentially expressed in various murine and human tissues [15]. To date, the functional differences and biological significance of these distinct isoforms have remained largely unexplored. Virtually all in vitro functional studies, including those on MM cell migration and adhesion, have exclusively employed the CXCL12 $\alpha$ isoform. Moreover, reported in vivo studies do not allow conclusions concerning the specific functions of the distinct CXCL12 isoforms, since the mice employed carried either a full deletion of CXCL12 or a deletion of CXCR4, the cognate receptor for all isoforms [16-19]. Interestingly, the recently characterized gamma

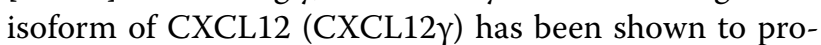
mote leukocyte accumulation and angiogenesis with a much higher efficacy than the 'canonical' CXCL12 $\alpha$ isoform [15]. This enhanced biological activity of CXCL12 $\gamma$ is mediated by its extended C-terminal domain, which binds heparan sulfate proteoglycans (HSPGs) with an unprecedentedly high affinity $[15,20,21]$. Notably, in mouse BM, CXCL12 $\gamma$ was reported to be the dominant CXCL12 isoform. Furthermore, mice with a partial deletion in the HSPG-binding motives of CXCL12 showed increased numbers of circulating HSCs, suggesting a role for CXCL12-HSPG interaction in the retention of HSCs in the BM [22].

HSPGs are membrane-bound or extracellular matrix proteins, consisting of a core protein decorated by covalently linked HS side chains composed of repeating disaccharide units. These HS chains undergo complex enzymatic modifications, which determine their binding capacity and specificity $[23,24]$ for a wide variety of morphogens, growth factor, and chemokines, thereby controlling the spatial distribution and activity of these ligands [25-27]. Given these properties, HSPGs appear well equipped to act as organizers of growth and survival niches. Indeed, studies in Drosophila have shown a crucial role for HSPGs in the germ cell as well as hematopoietic stem cell niches, controlling the activity of bone morphogenetic proteins (BMPs) $[28,29]$. In addition, HSPGs are known to bind a variety of proteins like Wnts, fibroblast growth factor (FGF), Midkine, and CXCL12, involved in the control of intestinal, neural, and hematopoietic niches $[25,26,30]$.

The extraordinary high affinity of CXCL12 $\gamma$ for HS, and its strong expression in mouse BM, prompted us to hypothesize that CXCL12 $\gamma$ could have a specific role in the organization of BM niches, including the plasma/ MM cell niche. To explore this notion, we investigated the expression of this CXCL12 isoform in human BM and studied its functional role in the interaction of $\mathrm{MM}$ cells with BMSCs cells.

\section{Materials and methods}

\section{Cell culture}

The human multiple myeloma cell lines (HMCLs) XG-1, MM1.S, and L363 were cultured as described previously [30]. For XG-1, medium was supplemented with $500 \mathrm{pg} /$ mL IL-6 (Prospec, Rehovot, Israel). BMSC lines HS5 and HS27a were cultured in DMEM (Invitrogen Life Technologies, Breda, The Netherlands) with 10\% FBS (Invitrogen Life Technologies), $100 \mu \mathrm{g} / \mathrm{ml}$ streptomycin, and 100 units/ml penicillin (Sigma-Aldrich, St Louis, USA), and bone marrow endothelial cell lines HBMEC60 and 4LHBMEC were cultured in EGM-2MV medium (Lonza, Geleen, The Netherlands). Primary MM cells and BMSCs were derived from MM patients diagnosed 
at the Amsterdam University Medical Centers, location AMC, Amsterdam, the Netherlands. This study was conducted and approved by the AMC Medical Committee on Human Experimentation. Informed consent was obtained in accordance with the Declaration of Helsinki.

\section{Cloning, transfection, and transduction}

pLenti-CRISPR-sgEXT1 was constructed by inserting sgRNA-EXT1 (GACCCAAGCCTGCGACCACG) into pL-CRISPR.EFS.GFP (Addgene plasmid \# 57818) as previously described [30]. pLenti-CRISPR-sgCXCL12 $\gamma$ was constructed by inserting sgRNA-CXCL12 $\gamma \# 1$ (TTT AACACTGGCCCGTGTAC) and sgRNA-CXCL12 $\gamma \# 2$ (AACTGTGGTCCATCTCGAGG) into pL-CRISPR.EFS. GFP [31]. pBABE-CXCL1 $2 \alpha$ and pBABE-CXCL12 $\gamma$ were constructed by inserting CXCL12 $\alpha$ or CXCL12 $\gamma$ cDNA containing C-terminally C9-tagged (TETSQVAPA) sequences into pBABE-puro (Addgene plasmid \# 1764). Lentiviral and retroviral particle production and transduction were performed as described before [30].

\section{Quantitative PCR and genomic DNA PCR}

Total RNA was isolated using TRI reagent (Invitrogen Life Technologies) according to the manufacturer's instructions and converted to cDNA using oligo-dT. Quantitative PCR was conducted using SensiFast (Bioline, London, UK) on the CFX384 RT-PCR detection system (Bio-Rad). Isoform-specific primers sequences and housekeeping gene primers are shown in Additional file 1: Table 1. Genomic DNA was isolated using QIAamp DNA kit according to the manufacturer's instructions. PCR primers used to detect CXCL12 $\gamma$ deletion are: forward primer: TCCCCAGTGGGAATCAGGTT; reverse primer: CTGGAGCTCCCAGGCTATTC.

\section{Adhesion assays}

CXCL12 $\alpha$ - and CXCL12 $\gamma$-induced adhesion to VCAM-1 was performed as described previously [32]. For adhesion to BMSCs and BM endothelial cells, MM cells were added to 96-well plates with confluent BMSCs or BM endothelial cells expressing a GFP marker. MM cells were spun down for $30 \mathrm{~s}$ at $400 \mathrm{RPM}$ and subsequently incubated for $20 \mathrm{~min}$ to allow adhesion of MM cells to BMSCs or BM endothelial cells. Non-adherent cells were removed by washing with RPMI containing $1 \%$ BSA. Adherent cells were detached by trypsin and quantified by flow cytometry.

\section{Co-culture assays}

For the co-culture assays, BMSCs were seeded in 96-well plates one day in advance to allow cell attachment. MM cells were added and incubated for $2 \mathrm{~h}$. Subsequently, drugs were added at the indicated concentrations. After
3 days, cells were collected and analyzed by flow cytometry, using 7-AAD (Thermo Fisher Scientific, Landsmeer, The Netherlands) to exclude dead cells. In the transwell assay, BMSCs were seeded in the lower compartment and MM cells in the transwell insert (Costar, $0.4 \mu \mathrm{m}$; Corning, USA). After culturing the cells for 3 days in the presence or absence of bortezomib, the cell viability was analyzed by flow cytometry.

\section{Cell surface protein staining}

Staining for HS was performed as described before [30]. Heparitinase used for digestion of cell surface HS was purchased from Amsbio (Abingdon, UK). For CXCL12 $\gamma$ cell surface staining, cells were detached by $2 \mu \mathrm{M}$ EDTA and stained with isotype-specific antibody 6E9. Primary antibody binding was detected with rabbit anti-mouse IgG1-APC (Southern Biotech, Birmingham, USA). To assess binding of recombinant CXCL12 $\gamma$, the HMCL

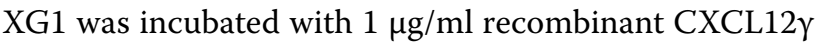
at $4{ }^{\circ} \mathrm{C}$ for $90 \mathrm{~min}$. After washing three times, cells were stained with $\mathrm{mAb} 6 \mathrm{E} 9$ and binding was detected with rabbit anti-mouse IgG1-APC (Southern Biotech), and the cells were analyzed by flow cytometry.

\section{Immunohistochemistry}

Paraffin-embedded MM patients and normal BM biopsies for immunohistochemical studies were obtained from the Department of Pathology, Amsterdam University Medical Centers, Loc. AMC (previous name: Academic Medical Center) Amsterdam, the Netherlands. Four-micrometer tissue sections were treated with TrisEDTA at $\mathrm{pH} 9$ for $20 \mathrm{~min}$ at $121{ }^{\circ} \mathrm{C}$ for antigen retrieval. Sections were incubated overnight at $4{ }^{\circ} \mathrm{C}$ with the CXCL12 $\gamma$ isoform-specific mAb 6E9. Subsequently, the tissues were washed with PBS and incubated with rabbit anti-mouse antibody (Southern Biotech) for $30 \mathrm{~min}$ at room temperature followed by poly-HRP anti-rabbit IgG (DPVR110HRP, Immunologic, Duiven, The Netherlands) and Ultra DAB (Immunologic).

\section{Results}

CXCL12 $\gamma$ is expressed by human BM reticular stromal cells

CXCL12 produced by specialized, CAR-like, BMSCs cells has been shown to mediate the homing of both HSCs, plasmablasts, and MM cells to the BM $[9,12]$. However, to date, the expression of specific CXCL12 isoforms in the human BM microenvironment, and their possibly distinctive roles in the interaction with $\mathrm{MM}$ cells, has remained unexplored. To study CXCL12 $\gamma$ expression in human BM in situ, we employed immunohistochemistry, using $\mathrm{mAb} 6 \mathrm{E} 9$ specific for this isoform [15]. Interestingly, the CXCL12 $\gamma$-positive cells identified were reticular stromal cells with long cytoplasmic processes, which 
were scattered among hematopoietic cells, around adipocytes and capillaries (Fig. 1a), areas with putative niche functions [33-38]. In BM samples infiltrated by $\mathrm{MM}$ cells, ample expression of CXCL12 $\gamma$ on stromal cells was also observed (Fig. 1a).

To define the expression of CXCL12 $\gamma$ by distinct BMderived stromal cell types, we studied primary human BMSCs, the BMSC lines HS5 and HS27a, and the human $\mathrm{BM}$ endothelial cell (HBMEC) lines 4L-HBMEC and HBMEC60. Furthermore, we assessed CXCL12 $\gamma$ expression in various HMCLs, including XG1, MM1.S and
L363. As shown in Fig. 1b, primary BMSCs as well as BMSC lines were found to express both CXCL12 $\gamma$ and CXCL12 $\alpha$ mRNA. By contrast, expression of both these CXCL12 isoforms was either low or undetectable in the HBMEC lines and in the HMCLs.

\section{CXCL12 $\gamma$ is immobilized on the cell surface of BMSCs by HSPGs}

The C-terminal domain of CXCL12 $\gamma$ contains three positively charged HSPG-binding motives $[15,20]$. Exogenous overexpression of CXCL12 $\gamma$ in HEK293T cells

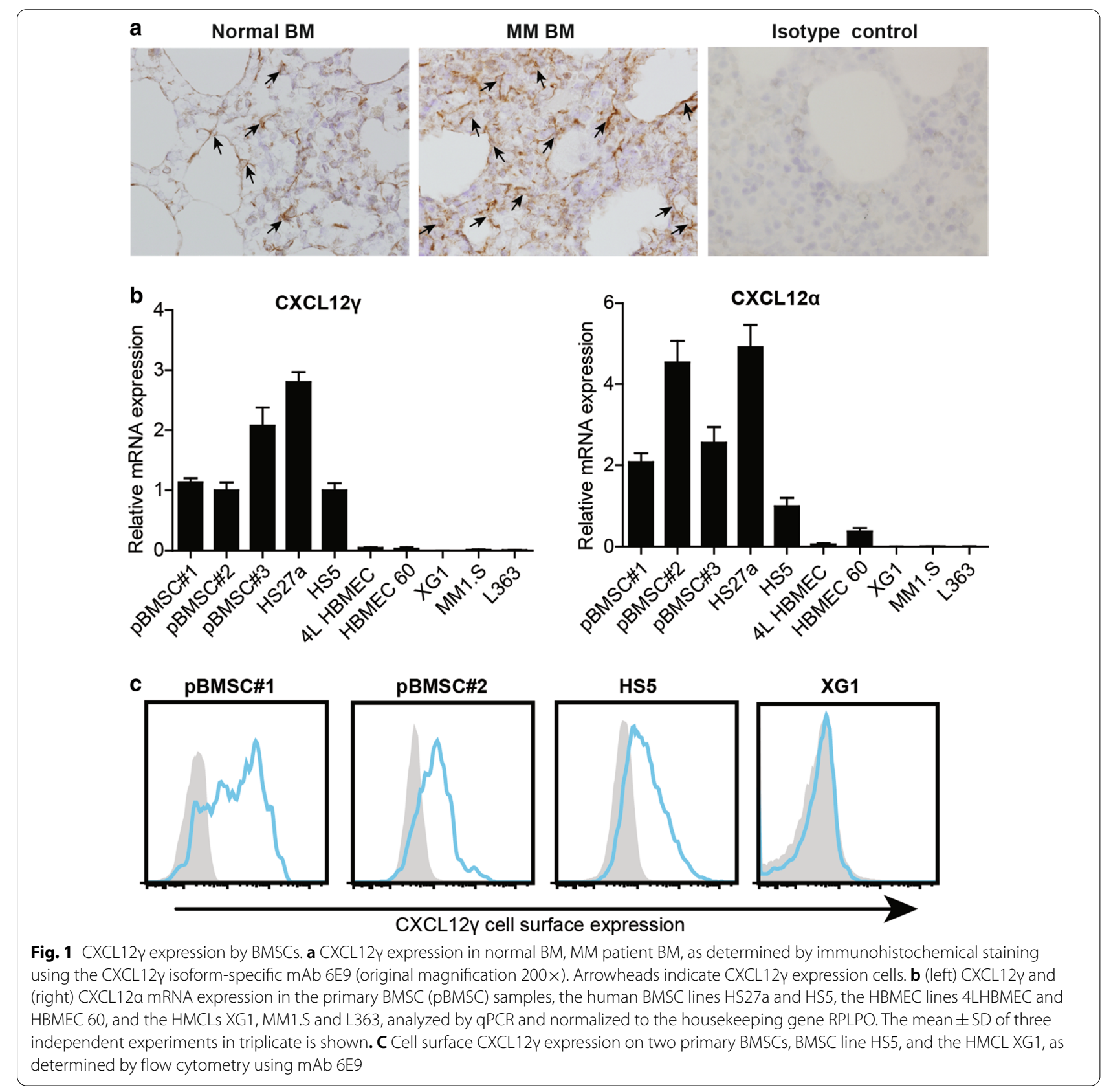


has shown that this domain interacts with cell surface expressed HSPGs, leading to immobilization on the cell membrane of the HEK293T cells [15]. We hypothesized that CXCL12 $\gamma$ expressed by BM reticular stromal cells might similarly be retained by HSPGs on the cell surface and thereby function as a membrane-bound chemokine. Indeed, by employing the CXCL12 $\gamma$-isoform-specific mAb 6E9, we observed that CXCL12 $\gamma$ is constitutively present on the cell membrane of both primary BMSCs and the BMSC line HS5. No membrane-bound CXCL12 $\gamma$ was detected on the HMCL XG1, which does not express CXCL12 $\gamma$ mRNA (Fig. 1c).

Both primary BMSCs and the BMSC line HS5 express high levels of cell surface HSPGs, as detected by the HS-specific mAb 10E4 (Fig. 2a). To study whether HS moieties indeed are responsible for the membraneretention of CXCL12 $\gamma$, we deleted EXT1, encoding the HS co-polymerase EXT1, which is critically required for the synthesis of HS chains [30]. EXT1 deletion in HS5 cells by CRISPR-Cas9 resulted in a complete loss of cell surface HS expression, which was paralleled by loss of membrane-bound CXCL12y (Fig. 2b). Similarly, enzymatic removal of HS (Fig. 2c, upper panel) from primary BMSCs by heparitinase resulted in a strong reduction of membrane-bound CXCL12 $\gamma$ (Fig. 2c, lower panel). The HMCL XG1 expresses the HSPG syndecan-1 [30] but does not express endogenous CXCL12 $\gamma$ (Fig. 1b, c). Incubation of XG1 cells with recombinant CXCL12 $\gamma$ resulted in strong membrane binding, which was attenuated by EXT1 deletion, corroborating the importance of HSPGs for CXCL12 $\gamma$ binding (Fig. 2d).

To assess whether membrane retention indeed is a unique feature of CXCL12 $\gamma$, not shared with the 'canonical' CXCL12 $\alpha$ isoform, we expressed either C9-tagged CXCL12 $\gamma$ or CXCL12 $\alpha$ in HS5 wild-type (WT) or HS5EXT1KO cells. Intracellular expression of both isoforms was readily detected in both HS5-WT and HS5-EXT1KO cells (Fig. 2e). However, membrane-bound CXCL12 $\gamma$ was detected only on the HS5-WT, but not on HS5-EXT1KO cells (Fig. 2e-left), demonstrating that CXCL12 $\gamma$ requires HS for membrane retention. CXCL12 $\alpha$, by contrast, was not retained on the surface of either HS5-WT and HS5EXT1KO cells (Fig. 2e-right). These data demonstrate that CXCL12 $\gamma$, unlike CXCL12 $\alpha$, is retained on the cell membrane of BMSCs by HSPGs.

\section{Recombinant CXCL12 $\gamma$ mediates MM cell adhesion to VCAM-1}

It is well established that CXCL12 $\alpha$ is able to induce VLA4-mediated adhesion of MM cells to VCAM-1 [32, 39]. To assess whether the $\gamma$-isoform of CXCL12 can similarly induce MM cell adhesion, the HMCLs XG1, MM1.S, and L363 were exposed to various concentrations of either recombinant CXCL12 $\alpha$ or CXCL12 $\gamma$. As shown in Fig. 3a, both CXCL12 $\alpha$ and CXCL12 $\gamma$ induced adhesion of these HMCLs to VCAM-1. The CXCL12 $\alpha$-induced adhesion showed a concentration-dependent bellshaped curve, typical for chemokine/CXCL12 $\alpha$-induced responses, with an optimum at $6.25 \mathrm{nmol}$. Remarkably, for CXCL12 $\gamma$-induced adhesion this bell-shaped doseresponse pattern was largely absent. At higher ligand concentrations, the CXCL12 $\gamma$-induced adhesion was sustained and much stronger than the adhesion induced by CXCL12 $\alpha$. Notably, induction of MM cell adhesion required coating of CXCL12 $\alpha$ and CXCL12 $\gamma$ to the adherence surface. In solution, both ligands were ineffective, indicating that CXCL12 immobilization is crucial for adhesion induction (Fig. 3b).

\section{CXCL12 $\gamma$ expressed and membrane-retained by HSPGs on reticular stromal cells mediates adhesion of MM cells} Given our finding that CXCL12 $\gamma$ is expressed and membrane-retained by stromal niche cells, we hypothesized that this isoform might play a specific role in controlling $\mathrm{MM}$ adhesion to and retention in the $\mathrm{BM}$ niche. To specifically study the biological function of CXCL12 $\gamma$, we employed two CRISPR sgRNAs designed to target the CXCL12 gene upstream and downstream of the fourth exon encoding the unique $\mathrm{C}$-terminal tail of CXCL12 $\gamma$ (Fig. 4a). Deletion in HS5 cells yielded a PCR product with a predicted size of approximately $500 \mathrm{bp}$ (Fig. 4a) and was verified by Sanger sequencing (Fig. 4b). Moreover, deletion was confirmed by loss of cell surface CXCL12 $\gamma$ protein expression (Fig. 4c). Importantly, as anticipated, the expression of CXCL12 $\alpha$ was not affected by deletion of exon 4 of the CXCL12 gene (Additional file 1: Figure S1). Furthermore, deletion of CXCL12 $\gamma$ had no effect on BMSC growth (Additional file 1: Figure S2).

As shown in Fig. 5a, the HMCLs XG1 and MM1.S displayed strong adhesion to HS5 and HS27 BMSCs, but did not adhere to BMECs. Interestingly, the capacity of HS5CXCL12 $\gamma \mathrm{KO}$ cells to support adhesion of these MM cells was significantly reduced (Fig. 5b and Additional file 1: Figure S3A). Likewise, the HS5-EXT1KO cells, which no longer express the HS moieties required for membrane retention of CXCL12 $\gamma$, also displayed a reduced capacity to support adhesion of these MM cells (Fig. 5c and Additional file 1: Figure S3B). Similar to the adhesion of HMCLs, primary MM cells also showed a reduced adhesion to HS5 BMSCs lacking either CXCL12 $\gamma$ or EXT1 (Fig. 5d). Importantly, exogenous reconstitution of CXCL12 $\gamma$ completely restored the adhesion defect in the HS5-CXCL12 $\gamma \mathrm{KO}$ BMSCs, confirming the role of CXCL12 $\gamma$. By contrast, exogenous overexpression of CXCL12 $\gamma$ in HS5-EXT1KO BMSCs could not rescue the defective adhesion of MM cells to these cells (Fig. 5e), 


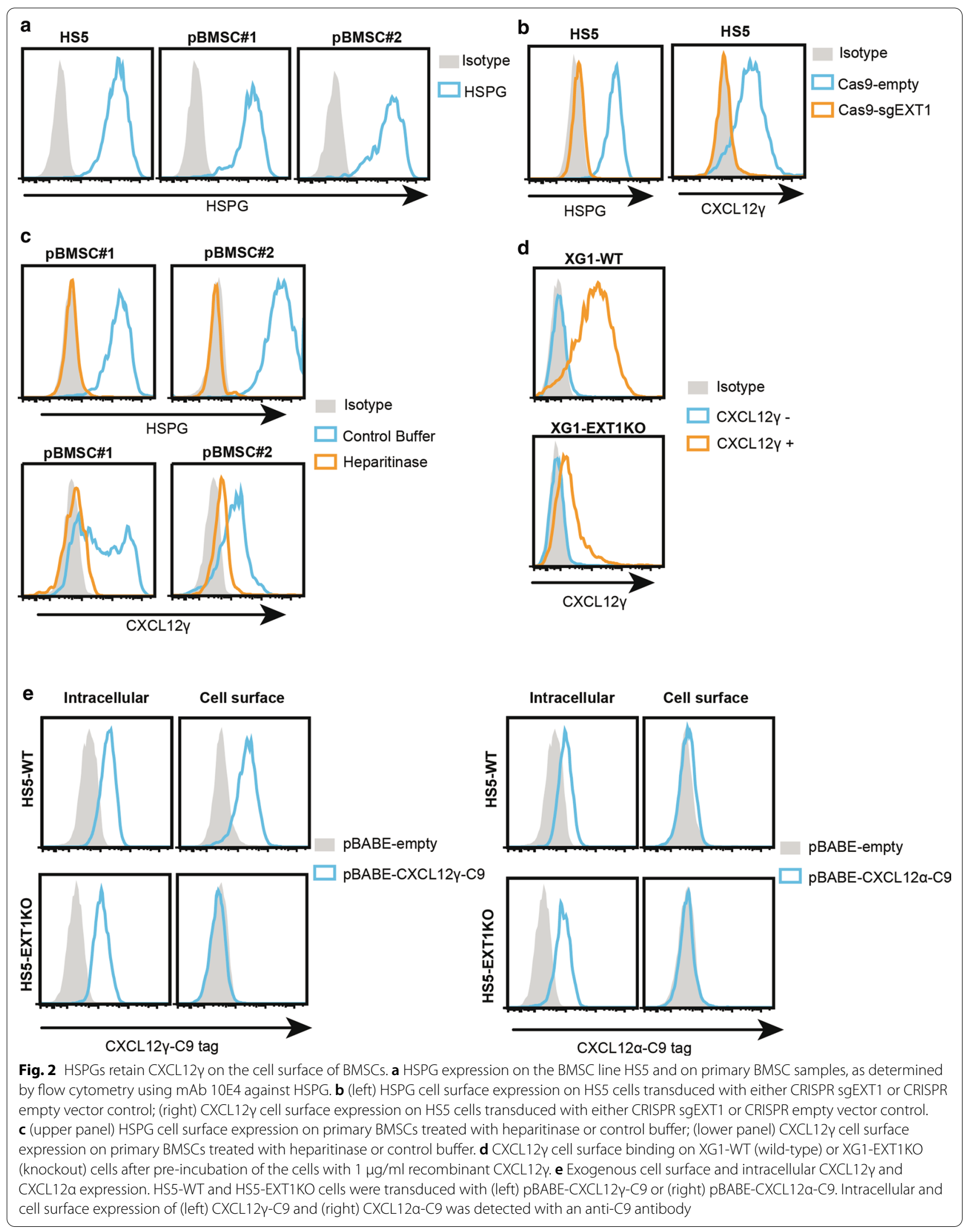




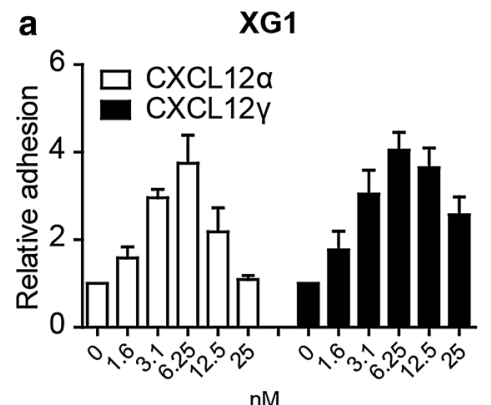

$\mathrm{nM}$

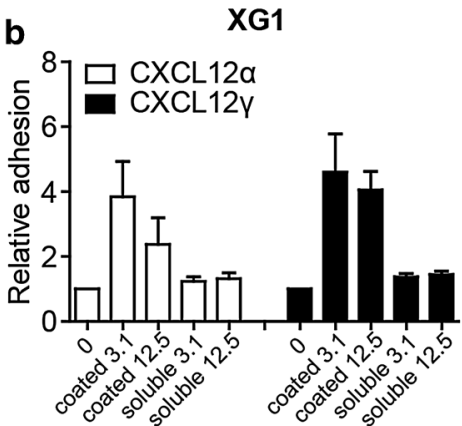

nM

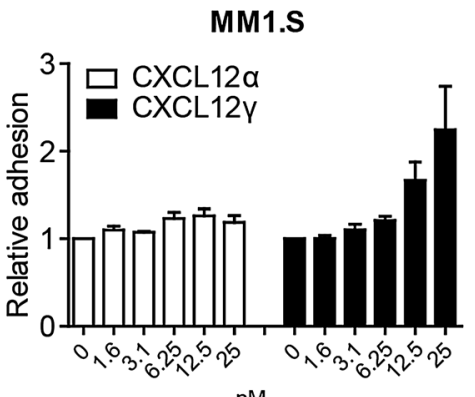

$\mathrm{nM}$

MM1.S

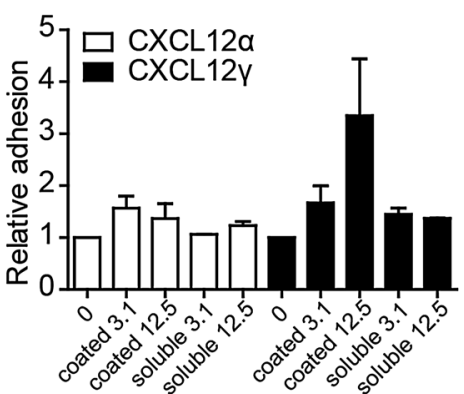

nM

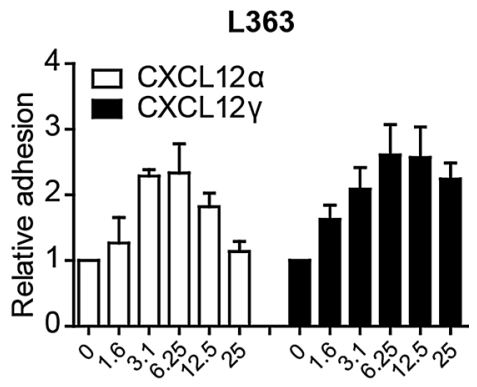

$\mathrm{nM}$

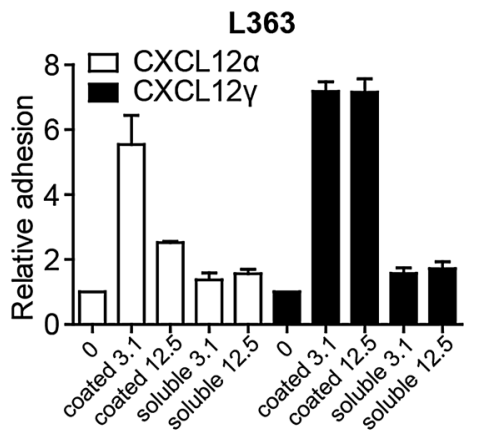

$\mathrm{nM}$

Fig. 3 CXCL12a and CXCL12 $\gamma$ induce MM cell adhesion to VCAM-1. a Adhesion of XG1, MM1.S, and L363 cells to a surface co-Coated with either VCAM-1 and CXCL12a or CXCL12 $\gamma$ at indicated concentrations. Adhesion was allowed for 2 min, and adhesion in the absence of CXCL12 was normalized to one. The mean \pm SD of at least three independent experiments in triplicate is shown. b Adhesion of XG1, MM1.S, and L363 cells to VCAM-1. CXCL12a or CXCL12y at indicated concentrations (nM) was either co-coated with VCAM-1 (coated) or present in the medium in soluble form (soluble). Adhesion in the absence of CXCL12 was normalized to one. Mean \pm SD of at least three independent experiments in triplicate is shown

confirming the critical role of HSPG-mediated CXCL12 $\gamma$ cell surface retention. Taken together, these data indicate that CXCL12 $\gamma$ expressed by BMSCs and immobilized by cell surface HSPGs plays an important role in mediating MM cell adhesion to BMSCs.

\section{CXCL12 $\gamma$ membrane-retained by HSPGs on BMSCs} mediates resistance of $M M$ cells to proteasome inhibitors Interaction of MM cells with BMSCs plays a central role in the homing, retention, growth, and survival of MM cells as well as in drug resistance [1, 2, 40, 41]. Inhibition of the CXCL12/CXCR4 axis, disrupting interaction of MM cells with BMSCs, has been reported to alleviate the protective effect of BMSCs, enhancing the sensitivity of MM cells to various drugs $[1,8]$. Given our observation that BMSC-derived CXCL12 $\gamma$ plays an important role in the adhesion of MM cells to BMSCs, we addressed the possible involvement of CXCL12 $\gamma$ in the protective effect of BMSCs against drug-induced MM cell death.

To measure MM cell death and the protective effect of BMSCs, the HMCLs XG1, MM1.S, and L363 or primary MM (pMM) cells were co-cultured with HS5 BMSCs expressing green fluorescent protein (GFP), to allow easy discrimination of both cell types (Additional file 1: Figure S4A). We focused on bortezomib since it represents a mainstay of current MM therapies. Moreover, unlike MM cells, which are highly sensitive, BMSCs are bortezomib insensitive in vitro (Additional file 1: Figure $\mathrm{S} 4 \mathrm{~B})$, allowing reliable quantification of MM-specific cell death. As shown in Fig. 6a-c, co-culture with HS5-WT BMSCs protected both HMCLs and pMMs from bortezomib-induced cell death. Interestingly, this protective effect was significantly reduced in MM cells co-cultured with HS5-CXCL12 $\gamma \mathrm{KO}$ cells, indicating involvement of CXCL12 $\gamma$ in mediating bortezomib resistance (Fig. 6a, c).

Since deletion of EXT1 results in loss of CXCL12 $\gamma$ membrane retention (Fig. 2b), we examined whether EXT1KO would also reduce the protective effect of BMSCs. Indeed, similar to HS5-CXCL12 $\gamma \mathrm{KO}$ cells, HS5-EXT1KO cells showed a significantly reduced capacity to protect both HMCLs and pMMs against bortezomib-induced cell death (Fig. 6b, c). Similarly,

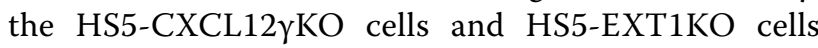
also showed a reduced capacity to protect XG1 against cell death induced by carfilzomib, another commonly used proteasome inhibitor (Additional file 1: Figure S5). 

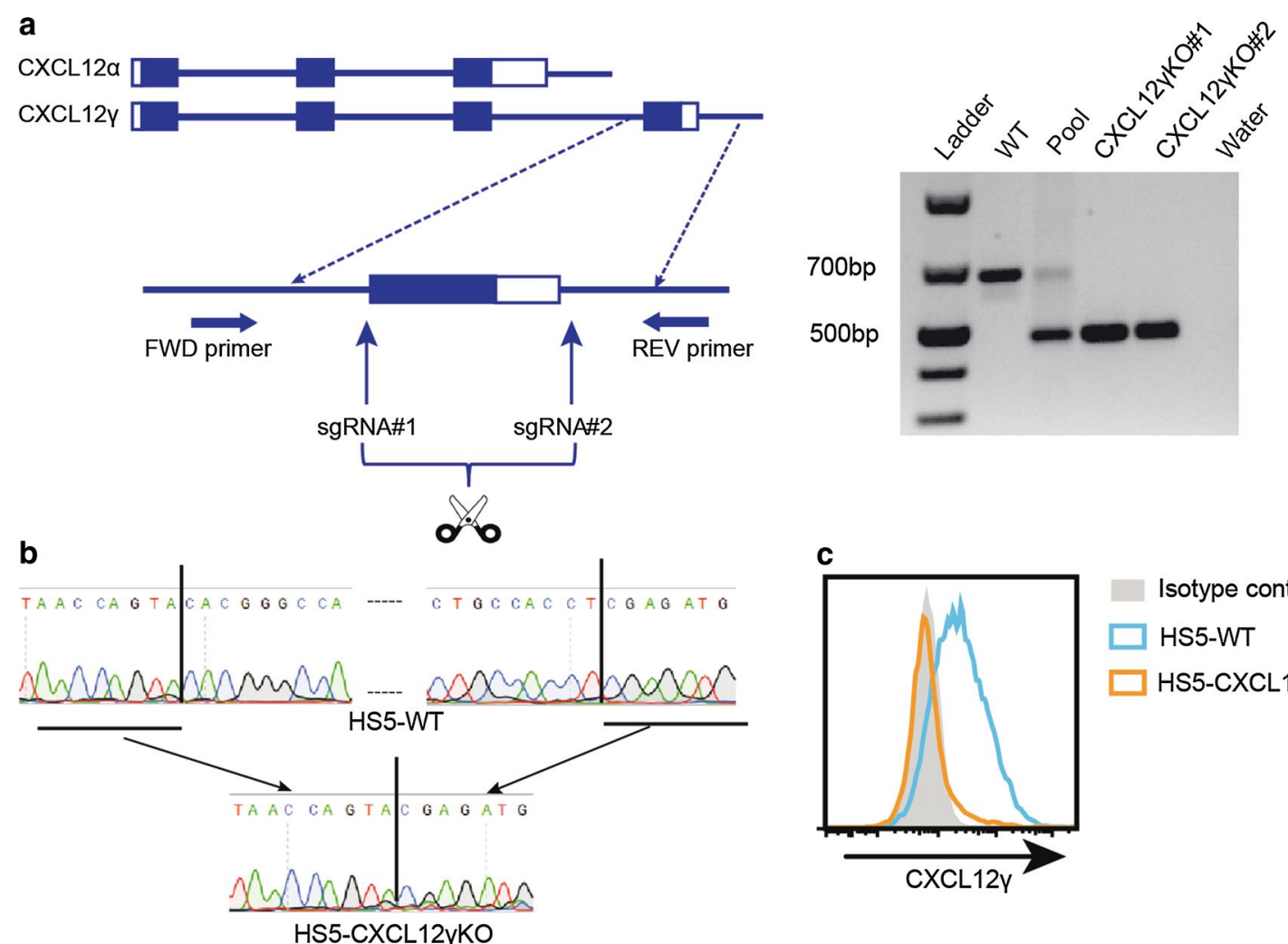

C

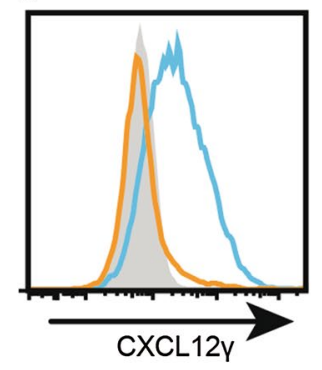

Isotype control

HS5-WT

HS5-CXCL12YKO

Fig. 4 Isoform-specific dual-sgRNA CRISPR-mediated CXCL12 $\gamma$ KO. a Schematic representation of the CRISPR-induced deletion of the fourth

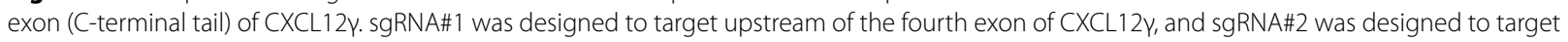
the $3^{\prime}$ UTR of the fourth exon. Rectangles represent exons, and filled rectangles represent coding sequences. Lines indicate introns. (Right) PCR analysis of the deletion of CXCL12y; primers used are as indicated in panel A. Genomic DNA was isolated from HS5 cells with the CRISPR empty vector (WT) or co-transduced with CRISPR sgRNA\#1 and CRISPR sgRNA\#2, either before single-cell cloning (pool) or from two single-cell KO clones (CXCL12YKO\#1 and \#2). Water was used as negative control. DNA ladder size is indicated on the left. $\mathbf{b}$ Confirmation of CRISPR-induced deletion by Sanger sequencing. Genomic DNA was isolated from HS5 cells transduced with empty vector CRISPR (HS5-WT) or CRISPR sgRNA\#1 and CRISPR sgRNA\#2 (HS5-CXCL12 $\gamma K O$ ). The CRISPR cutting sites are indicated by vertical line in HS5-WT; c Confirmation of CXCL12 $\gamma$ deletion by flow cytometry. Cell surface expression of CXCL12Y on HS5 cells transduced with either empty vector CRISPR (HS5-WT) or HS5-CXCL12YKO which were stained with the CXCL12Y-specific MAB 6E9

Recombinant CXCL12 $\gamma$ (or CXCL12 $\alpha$ ), in the absence of BMSCs, but co-coated with VCAM-1 did not affect the bortezomib sensitivity of HMCLs (Additional file 1: Figure S6a, b). These findings indicate that the BMSCmediated resistance to proteasome inhibitors involves CXCL12 $\gamma$ retained on the cell membrane of BMSCs by HSPGs.

\section{BMSC-derived CXCL12 $\gamma$ and HSPGs mediate CAM-DR}

Drug resistance mediated by the MM BM microenvironment can be caused either by soluble factors or by direct physical cell-cell interactions mediated by cell adhesion molecules, termed soluble factor-mediated drug resistance (SFM-DR) and cell adhesion-mediated drug resistance (CAM-DR), respectively $[1,42,43]$. To

\section{(See figure on next page.)}

Fig. 5 CXCL12 $\gamma$ retained by membrane-bound HSPGs promotes adhesion of MM cells to BMSCs. a Adhesion of the HMCLs XG1 and MM1.S to the BMSC lines HS5 and HS27a and the HBMEC lines 4LHBMEC and HMMEC-60. Adhesion to 4LHBMEC is normalized to one. Mean \pm SD of three independent experiments in triplicate is shown. $\mathbf{b}$ Adhesion of XG1 and MM1.S cells to HS5-WT and two independent CXCL12 $\gamma \mathrm{KO}$ clones. The mean $\pm \mathrm{SD}$ of three independent experiments in triplicate is shown. Adhesion to HS5-WT is normalized to one. ${ }^{* * *}, P \leq 0.001$ using one-way ANOVA. c Adhesion of XG1 and MM1.S cells to HS5-WT or HS5-EXT1KO cells. Mean \pm SD of three independent experiments in triplicate is shown. Adhesion to HS5-WT is normalized to one. ${ }^{*} P \leq 0.05 ;{ }^{* *} P \leq 0.01$ using unpaired Student's t-test. $\mathbf{d}$ Adhesion of primary MM cells from two patients to HS5-WT, HS5-CXCL12YKO, or HS5-EXT1KO cells. A representative plot for two independent experiments performed in triplicate is shown. ${ }^{*} P \leq 0.05$; ${ }^{* *} P \leq 0.01 ;{ }^{* *} P \leq 0.001$ using one-way ANOVA. e Adhesion of XG1 and MM1.S cells to HS5-WT, HS5-CXCL12 YKO, or HS5-EXT1KO cells transduced with either pBABE-empty or pBABE-CXCL12 $\gamma$ vector. Mean \pm SD of three independent experiments in triplicate is shown. ${ }^{* *} P \leq 0.01 ;{ }^{* * *} P \leq 0.001$ using one-way ANOVA 

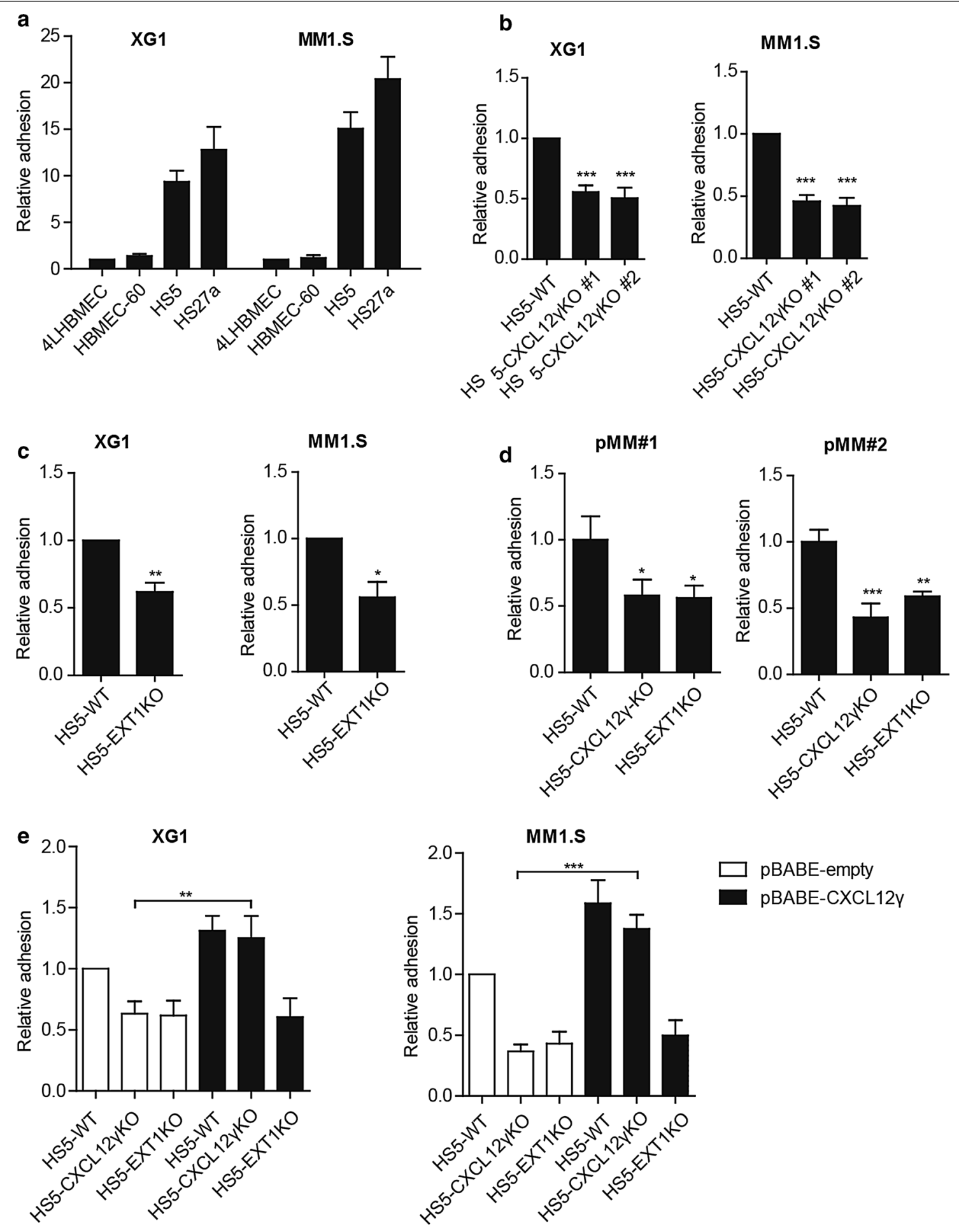

directly investigate the cell-cell contact dependency of the BMSC-mediated resistance to bortezomib and establish if soluble factors released by BMSCs were (also) involved, we employed transwell co-cultures to physically separate MM cells from BMSCs. As shown in Fig. 7a, in the transwell setting, HS5 BMSCs weakly, but significantly, protected the HMCL XG1, but not MM1.S, from bortezomib-induced cell death. This protective effect was 

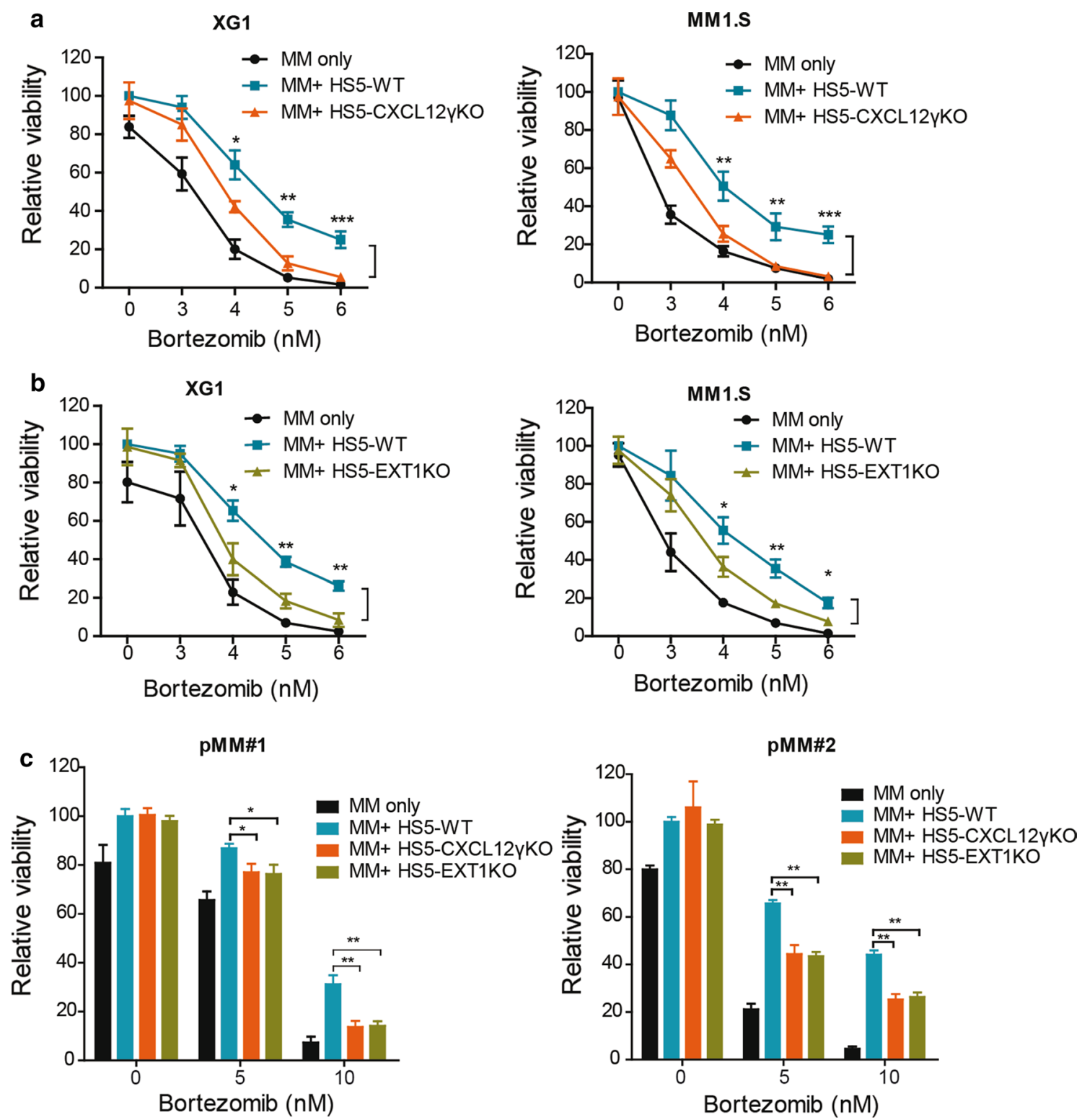

Fig. 6 BMSCs provide bortezomib-resistance to MM cells through CXCL12 $\gamma$ and HSPGs. a HS5-CXCL12 $\gamma$ KO cells show a reduced capacity to protect HMCLs from bortezomib-induced cell death. XG1 or MM1.S cells were cultured alone or co-cultured with HS5-WT or HS5-CXCL12YKO BMSCs, in the presence of bortezomib at indicated concentrations for 3 days. The viability of the MM cells was analyzed by flow cytometry. Mean \pm SD of three independent experiments in triplicate is shown. ${ }^{*} P \leq 0.05 ;{ }^{* *} P \leq 0.01 ;{ }^{* * *} P \leq 0.001$ using one-way ANOVA; $\boldsymbol{b}$ HS5-EXT1KO cells show a reduced capacity to protect HMCLs from bortezomib-induced cell death. XG1 and MM1.S cells were cultured alone or co-cultured with HS5-WT or HS5-EXT1KO BMSCs, in the presence of bortezomib at indicated concentrations for 3 days. The viability of the MM cells was analyzed by flow cytometry. Mean $\pm S D$ of three independent experiments in triplicate is shown. ${ }^{*} P \leq 0.05 ;{ }^{* *} P \leq 0.01$ using one-way ANOVA; c HS5-CXCL12үKO and HS5-EXT1KO cells show a reduced capacity to protect primary MM cells from bortezomib-induced cell death. Primary MM cells from two patients were cultured alone or co-cultured with HS5-WT, HS5-CXCL12үKO, or HS5-EXT1KO BMSCs, in the presence of bortezomib for 3 days. The viability of the MM cells was analyzed by flow cytometry. Plot representative for two independent experiments performed in triplicate. ${ }^{*} P \leq 0.05$; ${ }^{* *} P \leq 0.01$ using one-way ANOVA

not influenced by deletion of either CXCL12 $\gamma$ or EXT1. However, in a direct-contact setting, in which MM cells in suspension were removed before determining cell viability, BMSCs conferred a much stronger drug resistance to both XG1 and MM1.S. Importantly, this protective effect was largely abrogated by deletion of CXCL12 $\gamma$ or EXT1 and, hence, was CXCL12 $\gamma$ and HSPG dependent (Fig. 7b). Thus, CXCL12 $\gamma$ and HSPG on the cell surface 
of BMSCs promote MM cell adhesion to these BMSCs and thereby play an important role in CAM-DR.

\section{Discussion}

The CXCL12/CXCR4 axis plays a key role in the homing of normal plasma cell precursors and MM cells to the BM $[9,10]$, but the expression and specific role of CXCL12 $\gamma$, a recently characterized CXCL12 isoform, which binds HSPGs with an extremely high affinity, have not been addressed. Here, we show that CXCL12 $\gamma$ is expressed in situ by reticular stromal cells in the human bone marrow niche as well as by BMSC lines and primary BMSC isolates. Unlike CXCL12 $\alpha$, CXCL12 $\gamma$ is immobilized on the cell surface of BMSCs by HSPGs, upon secretion. Functionally, this membrane-bound CXCL12 $\gamma$ promotes adhesion of MM cells to the stromal niche cells, thereby protecting MM cells from drug-induced cell death.

Our study of the in situ expression of CXCL12y shows that it is expressed by CAR-like reticular stromal cells in the BM. In normal BM, distinct CXCL12 $\gamma$ expression was present on stromal cells with long cytoplasmic processes, scattered among hematopoietic cells, as well as around adipocytes and capillaries, and in the endosteal zone (Fig. 1a), areas with putative niche functions [3338]. In BM sections of MM patients, CXCL12 $\gamma$ was also observed on stromal cells in areas infiltrated by MM cells. Notably, employing an antibody against an epitope shared by all CXCL12 isoforms, Abe-Suzuki et al. [37] recently reported a similar expression pattern, which also resembles the distribution of CAR cells in mouse bone marrow [9]. Study of isolated primary BMSCs and BMSC lines corroborates these findings, demonstrating that CXCL12 $\gamma$ is specifically expressed by isolated primary BMSCs and BMSC lines (Fig. 1b).

CXCL12 $\gamma$ possesses an extraordinarily high affinity for HSPGs due to its unique C-terminal domain $[15,20]$. Interestingly, we observed that both primary BMCSs and
HS5 cells constitutively express CXCL12 $\gamma$ on their cell surface, suggesting that this chemokine is retained by HSPGs upon secretion (Fig. 1c). Indeed, we observed that $\mathrm{KO}$ of the HS-chain co-polymerase EXT1 in HS5 BMSCs results in a complete loss of membrane-bound CXCL12 $\gamma$. Importantly, immobilization by cell surface HS was a specific feature of the CXCL12 $\gamma$ isoform, since overexpression of CXCL12 $\alpha$ in HS5 did not result in detectable membrane retention, notwithstanding substantial intracellular expression (Fig. 2).

We observed that specific deletion of CXCL12 $\gamma$ strongly reduces the capacity of HS5 BMSCs to mediate adhesion of MM cells to their cell surface. This result extends the previous observation that a total (i.e., nonisoform specific) knockdown of CXCL12 reduces the capacity of BMSCs to mediate adhesion of MM cells [8], pinpointing this effect to the CXCL12 $\gamma$ isoform. Similar to CXCL12 $\gamma$ deletion, EXT1 deletion also attenuated MM cell adhesion to the BMSCs. Importantly, whereas the defective adhesion to HS5-CXCL12 $\gamma \mathrm{KO}$ cells could be overcome by exogenous expression of CXCL12 $\gamma$, this could not correct the adhesion defect in HS5-EXT1KO cells, indicating that CXCL12 $\gamma$ immobilization by HSPGs is critically required (Fig. 5). In line with this notion, in experiments employing recombinant CXCL12 to induce MM cell adhesion to VCAM-1 plastic, we observed that only immobilized (i.e. coated) CXCL12 effectively induced adhesion (Fig. 3b).

Interaction of MM cells with BMSCs plays a central role in MM cell homing/retention and can also confer drug resistance $[1,7]$. We observed that co-culture with HS5 BMSCs of the HMCLs XG1 and MM1.S and of primary MM cells did hardly or not affect tumor cell viability per se, but significantly reduced their sensitivity to the proteasome inhibitors bortezomib and carfilzomib. Interestingly, this resistance was largely annulled by specific

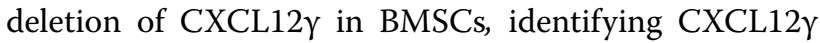

\footnotetext{
(See figure on next page.)

Fig. 7 BMSC-derived CXCL12 $\gamma$ immobilized by HSPGs mediates CAM-DR. a Transwells co-culture of MM cells with BMSCs. XG1 and MM1.S cells were cultured either alone in the upper compartment or co-cultured with HS5-WT, HS5-CXCL12үKO, or HS5-EXT1KO in the lower compartment of the transwells, in the presence of bortezomib for 3 days. So, the transwells physically separate the MM cells from the HS5 BMSCs. The viability of the MM cells was analyzed by flow cytometry. Mean \pm SD of three independent experiments in triplicate. ${ }^{*} P \leq 0.05$ using one-way ANOVA; b CXCL12 $\gamma$-controlled drug resistance requires direct cell-cell contact between MM cells and BMSCs. MM cells were cultured, either alone or co-cultured with HS5-WT, HS5-CXCL12YKO, or HS5-EXT1KO, in the presence of bortezomib for 3 days. The MM cells in suspension were removed. The viability of the remaining MM cells was analyzed by flow cytometry. Mean \pm SD of three independent experiments in triplicate is shown. ${ }^{* * *} P \leq 0.001$ using one-way ANOVA. c Model for the role of distinct CXCL12 isoforms in the MM BM niche. Specialized CAR-like BMSCs in the niche secrete high levels of CXCL12, including CXCL12 $a$ and CXCL12 $\gamma$. CXCL12a shows a relatively low affinity to HSPG and, upon secretion by BMSCs, will create a chemo-attractive gradient attracting MM cells to the niche. By contrast, CXCL12y, having an extremely high affinity for HSPG, will be immobilized by HSPGs on the cell surface of BMSCs, inducing MM adhesion to the BMSCs. This CXCL12 $\gamma$-controlled adhesion serves to retain MM cells in close physical contact with the BMSCs, providing MM cells with growth and survival signals through integrin receptors as well as with access to short-range growth and survival factors. This HSPG-immobilized CXCL12 $\gamma$ plays an important role in MM cell retention in the BM niche as well as in cell adhesion-mediated drug (CAM-DR) resistance in MM
} 
a

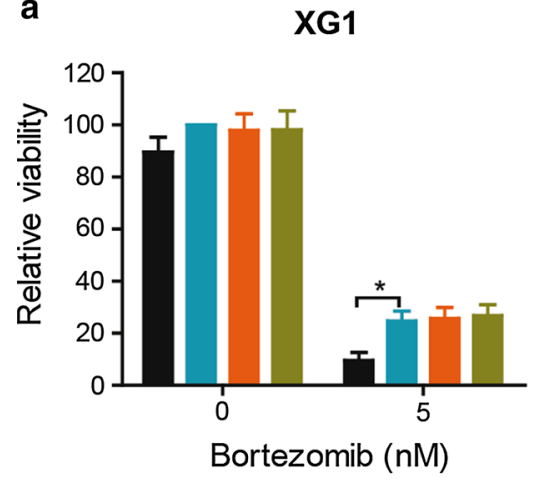

b

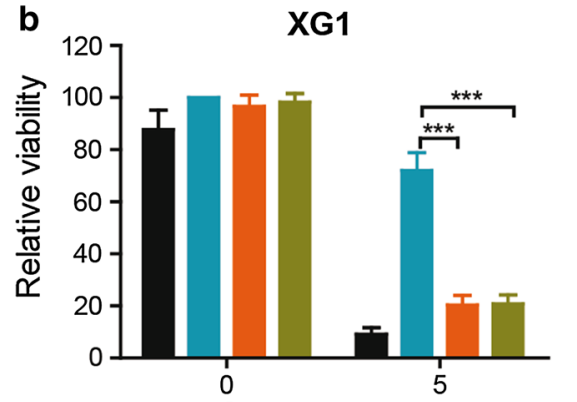

C

Bortezomib (nM)
MM1.S

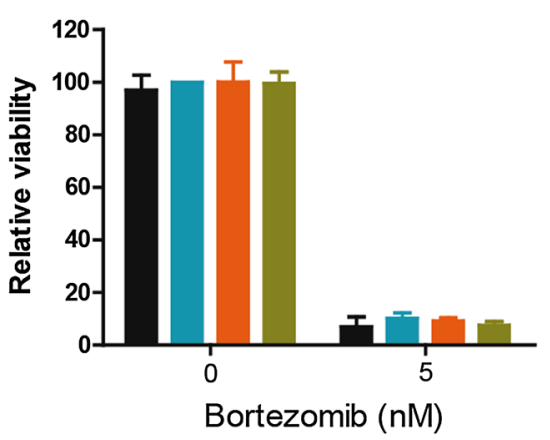

MM1.S

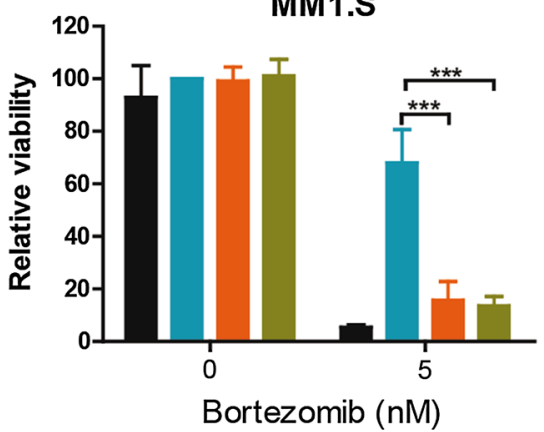

mM only

MM+ HS5-WT

MM+ HS5-CXCL12YKO

MM+ HS5-EXT1KO
MM only

MM+ HS5-WT

MM+ HS5-CXCL12YKO

MM+ HS5-EXT1KO

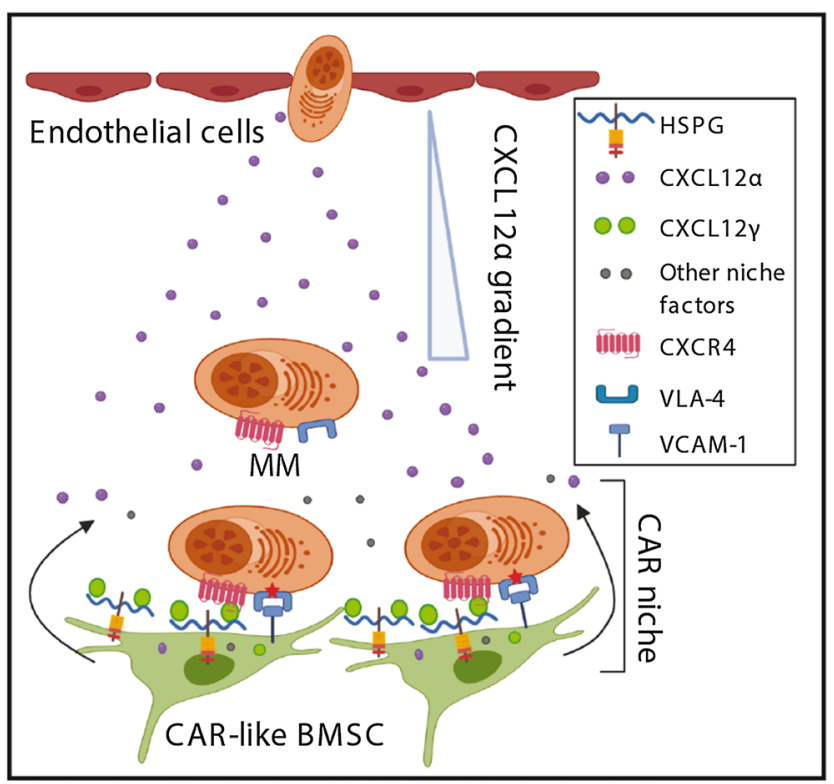

as a major factor in the BMSC-mediated drug resistance. HS5 BMSCs cells with a deletion of EXT-1 showed a similarly reduced capacity to protect $\mathrm{MM}$ cells, showing the essential role of membrane retention of CXCL12 $\gamma$ by HSPGs (Fig. 6).

Drug resistance mediated by BMSCs can be caused either by soluble factors or by interactions via cell adhesion molecules [1, 42, 43]. We observed that the protective effect of BMSCs to MM cells was largely abolished by physical separation of the MM and BMSCs, implying that this protection requires direct cell-cell contact (Fig. 7a, b). This suggests that BMSCs might convey MM drug resistance via direct integrin-mediated signals, rather than by soluble growth and survival 
factors, although such factors are abundantly expressed by BMSCs $[30,41,44]$. However, recombinant CXCL12 $\gamma$ (or CXCL12 $\alpha$ )-induced adhesion to VCAM-1-coated plastic did not protect $\mathrm{MM}$ cells against bortezomibinduced cell death (Additional file 1: Figure S6), indicating that integrin-mediated cell adhesion per se is not sufficient to instigate bortezomib resistance. Conceivably, CXCL12 $\gamma$-controlled adhesion serves to retain MM cells in close physical contact with the BMSCs, providing MM cells with growth and survival signals through integrin receptors as well as with access to short-range growth and survival factors, such as Wnts and vascular endothelial growth factor $[45,46]$, which may act in concert to mediate drug resistance.

Our data suggest targeting CXCL12 $\gamma$ and/or its interaction with HSPGs, as a potential therapeutic strategy. Notably, MM cells express high levels of the HSPG syndecan-1, which is crucial for MM cell survival [47, 48] and promotes Wnt-mediated cell proliferation [30] as well as hepatocyte growth factor (HGF), FGF, epidermal growth factor (EGF), and a proliferation-inducing ligand (APRIL)-mediated signaling [49-51]. Hence, targeting HSPGs or the HS biosynthesis machinery may disconnect the interaction of MM cells with the BM microenvironment at various levels [52]. Our studies corroborate previous studies, showing that disruption of the interaction between MM cells and BMSCs by the CXCR4 inhibitor AMD3100 enhances MM sensitivity to multiple therapeutic agents such as bortezomib, dexamethasone, and melphalan $[1,7$, 41]. Furthermore, targeting pan-CXCL12 by olaptesed pegol (ola-PEG), which neutralizes CXCL12 irrespective of the isoform, prevented $\mathrm{MM}$ progression in a murine model [8], while a recent phase IIa clinical trial showed that patients with relapsed/refractory MM respond favorably to a combination of bortezomib or dexamethasone with ola-PEG [53]. Apart from CXCR4, MM cells also express CXCR7, an alternative receptor of CXCL12, which may also be involved in CAM-DR in MM [7] as well as in MM progression [54]. Targeting the ligand CXCL12( $\gamma$ ) will simultaneously inhibit signaling through both chemokine receptors. It will also be of interest to explore whether CXCL12 $\gamma$ plays similar roles in the interaction of other hematological malignancies with the BM microenvironment, including acute myeloid leukemia (AML) and non-Hodgkin lymphomas.

\section{Conclusions}

Taken together, our data suggest a scenario in which CXCL12 $\gamma$ functions as a 'niche chemokine' that, in conjunction with HSPGs, plays a key role in controlling adhesion, BM retention, and CAM-DR of MM cells (Fig. 7c).These findings identify this unique membranebound chemokine,and associated HSPGs, as potential therapeutic targets in MM.

\section{Supplementary information}

Supplementary information accompanies this paper at https://doi. org/10.1186/s13045-021-01031-3.

Additional file 1. The CXCL12 $\gamma$ chemokine immobilized by heparan sulfate on stromal niche cells controls adhesion and mediates drug resistance in multiple myeloma

\section{Abbreviations}

MM: Multiple myeloma; BM: Bone marrow; HSPGs: Heparan sulfate proteoglycans; BMSCs: Bone marrow stromal cells; HSCs: Hematopoietic stem cells; CAR : CXCL12-abundant reticular; BMPs: Morphogenetic proteins; FGF: Fibroblast growth factor; HMCLs: Human multiple myeloma cell lines; SFM-DR: Soluble factor-mediated drug resistance; CAM-DR: Cell adhesion-mediated drug resistance; HGF: Hepatocyte growth factor; EGF: Epidermal growth factor; APRIL: A proliferation-inducing ligand.

\section{Acknowledgements}

We thank members of our team for critical discussion and suggestions. We also thank patients participated in our study.

\section{Authors' contributions}

ZR designed the research, performed experiments, analyzed the data, designed the figures, and wrote the paper; HL, AK, and WK performed experiments. MJK and FAS provided materials. MS and STP supervised the study, designed the research, and analyzed the data. STP wrote the paper. All authors read and approved the final manuscript.

\section{Funding}

This work was supported by Grant UVA 2011-5205 from the Dutch Cancer Society to MS and STP, by a Grant from Lymph\&Co to STP and MJK, and by a CSC Chinese Government Scholarship to ZR.

\section{Availability of data and materials}

All data generated or analyzed during this study are included in this published article (and its additional files).

\section{Ethics approval and consent to participate}

Primary MM cells and BMSCs were derived from MM patients diagnosed at the Amsterdam University Medical Centers, location AMC, Amsterdam, the Netherlands. This study was conducted and approved by the AMC Medical Committee on Human Experimentation. Informed consent was obtained in accordance with the Declaration of Helsinki.

\section{Consent for publication}

Consent for publication is not applicable for this article.

\section{Competing interests}

The authors declare no competing interests.

\section{Author details}

${ }^{1}$ Department of Pathology, Amsterdam University Medical Centers, Loc. AMC, Meibergdreef 9, 1105 AZ Amsterdam, The Netherlands. ${ }^{2}$ Lymphoma and Myeloma Center Amsterdam - LYMMCARE, and Cancer Center Amsterdam (CCA), Amsterdam, The Netherlands. ${ }^{3}$ Department of Virology, Institut Pasteur, Paris, France. ${ }^{4}$ Department of Hematology, Amsterdam UMC, University of Amsterdam, Amsterdam, The Netherlands.

Received: 16 September 2020 Accepted: 1 January 2021

Published online: 12 January 2021 


\section{References}

1. Azab AK, Runnels JM, Pitsillides C, Moreau AS, Azab F, Leleu X, et al. CXCR4 inhibitor AMD3100 disrupts the interaction of multiple myeloma cells with the bone marrow microenvironment and enhances their sensitivity to therapy. Blood. 2009;113(18):4341-51.

2. Hideshima T, Mitsiades C, Tonon G, Richardson PG, Anderson KC. Understanding multiple myeloma pathogenesis in the bone marrow to identify new therapeutic targets. Nat Rev Cancer. 2007;7(8):585-98.

3. Pagnucco G, Cardinale G, Gervasi F. Targeting multiple myeloma cells and their bone marrow microenvironment. Ann NY Acad Sci. 2004;1028:390-9.

4. Gay F, Magarotto V, Crippa C, Pescosta N, Guglielmelli T, Cavallo F, et al. Bortezomib induction, reduced-intensity transplantation, and lenalidomide consolidation-maintenance for myeloma: updated results. Blood. 2013;122(8):1376-83.

5. Engelhardt M, Terpos E, Kleber M, Gay F, Wasch R, Morgan G, et al. European Myeloma Network recommendations on the evaluation and treatment of newly diagnosed patients with multiple myeloma. Haematologica. 2014;99(2):232-42.

6. van de Donk NW, Moreau P, Plesner T, Palumbo A, Gay F, Laubach JP, et al. Clinical efficacy and management of monoclonal antibodies targeting CD38 and SLAMF7 in multiple myeloma. Blood. 2016;127(6):681-95.

7. Waldschmidt JM, Simon A, Wider D, Muller SJ, Follo M, lhorst G, et al. CXCL12 and CXCR7 are relevant targets to reverse cell adhesionmediated drug resistance in multiple myeloma. $\mathrm{Br} J$ Haematol. 2017;179(1):36-49.

8. Roccaro AM, Sacco A, Purschke WG, Moschetta M, Buchner K, Maasch C, et al. SDF-1 inhibition targets the bone marrow niche for cancer therapy. Cell Rep. 2014;9(1):118-28.

9. Sugiyama T, Kohara H, Noda M, Nagasawa T. Maintenance of the hematopoietic stem cell pool by CXCL12-CXCR4 chemokine signaling in bone marrow stromal cell niches. Immunity. 2006;25(6):977-88.

10. Peled A, Petit I, Kollet O, Magid M, Ponomaryov T, Byk T, et al. Dependence of human stem cell engraftment and repopulation of NOD/SCID mice on CXCR4. Science (New York, NY). 1999;283(5403):845-8.

11. Sanz-Rodriguez F, Hidalgo A, Teixido J. Chemokine stromal cell-derived factor-1alpha modulates VLA-4 integrin-mediated multiple myeloma cell adhesion to CS-1/fibronectin and VCAM-1. Blood. 2001;97(2):346-51.

12. Alsayed $Y, N_{\text {go }} H$, Runnels J, Leleu $X$, Singha UK, Pitsillides $C M$, et al. Mechanisms of regulation of CXCR4/SDF-1 (CXCL12)-dependent migration and homing in multiple myeloma. Blood. 2007;109(7):2708-17.

13. Menu E, Asosingh K, Indraccolo S, De Raeve H, Van Riet I, Van Valckenborgh $E$, et al. The involvement of stromal derived factor 1alpha in homing and progression of multiple myeloma in the 5TMM model. Haematologica. 2006;91(5):605-12.

14. Yu L, Cecil J, Peng SB, Schrementi J, Kovacevic S, Paul D, et al. Identification and expression of novel isoforms of human stromal cell-derived factor 1. Gene. 2006;374:174-9.

15. Rueda P, Balabanian K, Lagane B, Staropoli I, Chow K, Levoye A, et al. The CXCL12gamma chemokine displays unprecedented structural and functional properties that make it a paradigm of chemoattractant proteins. PLOS ONE. 2008;3(7):e2543.

16. Zou YR, Kottmann AH, Kuroda M, Taniuchi I, Littman DR. Function of the chemokine receptor CXCR4 in haematopoiesis and in cerebellar development. Nature. 1998:393(6685):595-9.

17. Zhu W, Liang G, Huang Z, Doty SB, Boskey AL. Conditional inactivation of the CXCR4 receptor in osteoprecursors reduces postnatal bone formation due to impaired osteoblast development. J Biol Chem. 2011;286(30):26794-805.

18. Nagasawa T, Hirota S, Tachibana K, Takakura N, Nishikawa S, Kitamura Y, et al. Defects of B-cell lymphopoiesis and bone-marrow myelopoiesis in mice lacking the CXC chemokine PBSF/SDF-1. Nature. 1996;382(6592):635-8.

19. Takabatake Y, Sugiyama T, Kohara H, Matsusaka T, Kurihara H, Koni PA, et al. The CXCL12 (SDF-1)/CXCR4 axis is essential for the development of renal vasculature. J Am Soc Nephrol. 2009:20(8):1714-23.

20. Laguri C, Sadir R, Rueda P, Baleux F, Gans P, Arenzana-Seisdedos F, et al. The novel CXCL12gamma isoform encodes an unstructured cationic domain which regulates bioactivity and interaction with both glycosaminoglycans and CXCR4. PLoS ONE. 2007;2(10):e1110.
21. Connell BJ, Sadir R, Baleux F, Laguri C, Kleman JP, Luo L, et al. Heparan sulfate differentially controls CXCL12alpha- and CXCL12gamma-mediated cell migration through differential presentation to their receptor CXCR4. Science Signal. 2016;9(452):ra107.

22. Rueda P, Richart A, Recalde A, Gasse P, Vilar J, Guerin C, et al. Homeostatic and tissue reparation defaults in mice carrying selective genetic invalidation of CXCL12/proteoglycan interactions. Circulation. 2012;126(15):1882-95.

23. Esko JD, Selleck SB. Order out of chaos: assembly of ligand binding sites in heparan sulfate. Annu Rev Biochem. 2002;71:435-71.

24. Hacker U, Nybakken K, Perrimon N. Heparan sulphate proteoglycans: the sweet side of development. Nat Rev Mol Cell Biol. 2005;6(7):530-41.

25. Xu D, Esko JD. Demystifying heparan sulfate-protein interactions. Annu Rev Biochem. 2014:83:129-57.

26. Reijmers RM, Spaargaren M, Pals ST. Heparan sulfate proteoglycans in the control of B cell development and the pathogenesis of multiple myeloma. FEBS J. 2013;280(10):2180-93.

27. Ramani VC, Purushothaman A, Stewart MD, Thompson CA, Vlodavsky I, $\mathrm{Au} J \mathrm{~L}$, et al. The heparanase/syndecan-1 axis in cancer: mechanisms and therapies. FEBS J. 2013;280(10):2294-306.

28. Guo Z, Wang Z. The glypican Dally is required in the niche for the maintenance of germline stem cells and short-range BMP signaling in the Drosophila ovary. Development (Cambridge, England). 2009;136(21):3627-35.

29. Pennetier D, Oyallon J, Morin-Poulard I, Dejean S, Vincent A, Crozatier M. Size control of the Drosophila hematopoietic niche by bone morphogenetic protein signaling reveals parallels with mammals. Proc Natl Acad Sci USA. 2012;109(9):3389-94.

30. Ren Z, van Andel H, de Lau W, Hartholt RB, Maurice MM, Clevers H, et al. Syndecan-1 promotes Wnt/beta-catenin signaling in multiple myeloma by presenting Wnts and R-spondins. Blood. 2018;131(9):982-94.

31. Heckl D, Kowalczyk MS, Yudovich D, Belizaire R, Puram RV, McConkey ME, et al. Generation of mouse models of myeloid malignancy with combinatorial genetic lesions using CRISPR-Cas9 genome editing. Nat Biotechnol. 2014;32(9):941-6.

32. de Rooij MF, Kuil A, Geest CR, Eldering E, Chang BY, Buggy JJ, et al. The clinically active BTK inhibitor PCl-32765 targets B-cell receptor-and chemokine-controlled adhesion and migration in chronic lymphocytic leukemia. Blood. 2012;119(11):2590-4

33. Bonomo A, Monteiro AC, Goncalves-Silva T, Cordeiro-Spinetti E, Galvani RG, Balduino A. A T cell view of the bone marrow. Front Immunol. 2016;7:184

34. Morrison SJ, Scadden DT. The bone marrow niche for haematopoietic stem cells. Nature. 2014;505(7483):327-34.

35. Ribatti D, Basile A, Ruggieri S, Vacca A. Bone marrow vascular niche and the control of angiogenesis in multiple myeloma. Front Biosci (Landmark Ed). 2014;19:304-11.

36. Ribatti D, Nico B, Vacca A. Multiple myeloma as a model for the role of bone marrow niches in the control of angiogenesis. Int Rev Cell Mol Biol. 2015:314:259-82

37. Abe-Suzuki S, Kurata M, Abe S, Onishi I, Kirimura S, Nashimoto M, et al. CXCL12+ stromal cells as bone marrow niche for CD34+ hematopoietic cells and their association with disease progression in myelodysplastic syndromes. Lab Investig J Tech Methods Pathol. 2014;94(11):1212-23.

38. Omatsu Y, Sugiyama T, Kohara H, Kondoh G, Fujii N, Kohno K, et al. The essential functions of adipo-osteogenic progenitors as the hematopoietic stem and progenitor cell niche. Immunity. 2010;33(3):387-99.

39. Azab AK, Azab F, Blotta S, Pitsillides CM, Thompson B, Runnels JM, et al. RhoA and Rac1 GTPases play major and differential roles in stromal cell-derived factor-1-induced cell adhesion and chemotaxis in multiple myeloma. Blood. 2009;114(3):619-29.

40. Di Marzo L, Desantis V, Solimando AG, Ruggieri S, Annese T, Nico B, et al. Microenvironment drug resistance in multiple myeloma: emerging new players. Oncotarget. 2016;7(37):60698-711.

41. Ghobrial IM, Detappe A, Anderson KC, Steensma DP. The bone-marrow niche in MDS and MGUS: implications for AML and MM. Nat Rev Clin Oncol. 2018;15(4):219-33.

42. Gupta D, Treon SP, Shima Y, Hideshima T, Podar K, Tai YT, et al. Adherence of multiple myeloma cells to bone marrow stromal cells upregulates vascular endothelial growth factor secretion: therapeutic applications. Leukemia. 2001;15(12):1950-61. 
43. Hideshima T, Nakamura N, Chauhan D, Anderson KC. Biologic sequelae of interleukin-6 induced PI3-K/Akt signaling in multiple myeloma. Oncogene. 2001;20(42):5991-6000.

44. Rougier F, Cornu E, Praloran V, Denizot Y. IL-6 and IL-8 production by human bone marrow stromal cells. Cytokine. 1998;10(2):93-7.

45. Farin HF, Jordens I, Mosa MH, Basak O, Korving J, Tauriello DV, et al. Visualization of a short-range Wnt gradient in the intestinal stem-cell niche. Nature. 2016;530(7590):340-3.

46. Barkefors I, Le Jan S, Jakobsson L, Hejll E, Carlson G, Johansson H, et al. Endothelial cell migration in stable gradients of vascular endothelial growth factor $\mathrm{A}$ and fibroblast growth factor 2: effects on chemotaxis and chemokinesis. J Biol Chem. 2008;283(20):13905-12

47. Yang Y, MacLeod V, Dai Y, Khotskaya-Sample Y, Shriver Z, Venkataraman G, et al. The syndecan-1 heparan sulfate proteoglycan is a viable target for myeloma therapy. Blood. 2007;110(6):2041-8.

48. Reijmers RM, Groen RW, Rozemuller H, Kuil A, de Haan-Kramer A, Csikos T, et al. Targeting EXT1 reveals a crucial role for heparan sulfate in the growth of multiple myeloma. Blood. 2010;115(3):601-4

49. Derksen PW, Keehnen RM, Evers LM, van Oers MH, Spaargaren M, Pals ST. Cell surface proteoglycan syndecan-1 mediates hepatocyte growth factor binding and promotes Met signaling in multiple myeloma. Blood. 2002;99(4):1405-10.

50. Mahtouk K, Cremer FW, Reme T, Jourdan M, Baudard M, Moreaux J, et al. Heparan sulphate proteoglycans are essential for the myeloma cell growth activity of EGF-family ligands in multiple myeloma. Oncogene. 2006;25(54):7180-91.
51. Reijmers RM, Groen RW, Kuil A, Weijer K, Kimberley FC, Medema JP, et al. Disruption of heparan sulfate proteoglycan conformation perturbs B-cell maturation and APRIL-mediated plasma cell survival. Blood. 2011;117(23):6162-71.

52. Sanderson RD, Yang Y. Syndecan-1: a dynamic regulator of the myeloma microenvironment. Clin Exp Metas. 2008;25(2):149-59.

53. Ludwig H, Weisel K, Petrucci MT, Leleu X, Cafro AM, Garderet L, et al. Olaptesed pegol, an anti-CXCL12/SDF-1 Spiegelmer, alone and with bortezomib-dexamethasone in relapsed/refractory multiple myeloma: a Phase lla Study. Leukemia. 2017;31(4):997-1000.

54. Azab AK, Sahin I, Moschetta M, Mishima Y, Burwick N, Zimmermann J, et al. CXCR7-dependent angiogenic mononuclear cell trafficking regulates tumor progression in multiple myeloma. Blood. 2014;124(12):1905-14.

\section{Publisher's Note}

Springer Nature remains neutral with regard to jurisdictional claims in published maps and institutional affiliations.
Ready to submit your research? Choose BMC and benefit from:

- fast, convenient online submission

- thorough peer review by experienced researchers in your field

- rapid publication on acceptance

- support for research data, including large and complex data types

- gold Open Access which fosters wider collaboration and increased citations

- maximum visibility for your research: over 100M website views per year

At BMC, research is always in progress.

Learn more biomedcentral.com/submissions 